\section{What's wrong with being neutral?}

\author{
Theodore K. Rabb
}

Climate Impact Assessment. SCOPE Report 27. Edited by Robert W. Kates, Jesse H. Ausubel and Mimi Berberian. Wiley:1985. Pp.625. £59, \$100.

SCIENTISTS are understandably shy of making doomsday predictions. Even when their investigations uncover what some might consider frightening possibilities, they incline to caution. The calculations are uncertain, extrapolations are full of pitfalls and nobody is sure what the consequences for humanity of specific events might be. No area of science is more fraught with such hesitations than the study of the effects of climatic change.

The editors of Climate Impact Assessment have put together a breathtaking survey of what has been accomplished in over three decades of research in four main areas: overall models and frameworks for assessing climatic impacts; the impact in specific sectors such as agriculture and water resources; the impact on particular societies and their response; and the construction (often by modelling) of integrated assessments. But the emphasis throughout is on neutral interpretation. For example, because short-term changes are much larger and therefore mask longterm changes, it is said on p. 42 that one should withhold judgement on the rise in the concentration of carbon dioxide in the atmosphere - this, when $1.5 \times 10^{10}$ tons are being added each year, and an almost equivalent tonnage of ozone is being lost (p.505). Similarly, neither observed changes nor their variability are "significant" (p. 40) - to whom? And narrative descriptions of climatic disasters, containing such rhetoric as "crippling", are to be avoided, because "the unwary reader" may not discern the absence "of a precise framework for gauging the importance of climatic impact" (p. 543). The measured tone, the rap on the knuckles for the few unruly children who do make urgent noises - this is the seventeenth-century heritage of science as an escape from emotion taken (at least for this field) too far.

References to the level of carbon dioxide in the atmosphere recur throughout the 22 essays in this book. But all of the authors treat it as a valuable statistic, as a stimulus to research or as a fascinating academic question. Thus (p. 509):

An increase in the average temperature by 3 or $4^{\circ} \mathrm{C}$ could lead to the beginning of an irreversible melting of glaciers. What will the properties of the new state of equilibrium of the biosphere be like; will they permit the existence of man? We do not know.
Those who have suggested they do know, and have foreseen terrifying dislocations as the Earth's landmass shrinks dramatically, tend to be relegated to the fringes of scholarship. They are scarcely mentioned in this book, as if they might somehow tarnish the respectability of the field. One has the feeling that perhaps everyone is hoping that the dire predictions will balance out - that the greenhouse effect might be counteracted by the cyclical return of an ice age - so that what Thomas Kuhn called "normal" science can proceed undisturbed.

Yet the basic facts are inescapable. Given the comment in the quotation above about a 3 or $4^{\circ} \mathrm{C}$ temperature rise, what is one to make of the $2^{\circ} \mathrm{C}$ rise that has taken place in Indiana over the past century (p. 61)? One answer emerges unmistakably: recognition of a potential problem is crucial if a society is to have any interest in addressing it. A 30 per cent increase in summer rainfall recently went unnoticed by the citizens of St Louis (pp. 324 -326). People do make small adjustments, of course; but what is likely to follow if - as has happened - a fundamental but imperceptible shift takes place, such as a displacement of the northern limit of a particular crop's viability more than $300 \mathrm{~km}$ southward over the course of a century (p. 365)? Do we throw more chemicals at it? Relocate or retrain the populations of entire regions?

None of this is to suggest that there is no real concern about the issues in the scientific community. The Carbon Dioxide Information Center at Oak Ridge National Laboratory is one of a number of organizations that keeps trying to draw our attention to the need for both research and action. But it is the former that takes precedence over the latter, and by a long way. A briefer version of the thorough review of the scholarly literature in Cli- mate Impact Assessment appeared in Kellogg and Schware's study of the consequences of the build-up of carbon dioxide (Climate Change and Society, published by the National Center for Atmcspheric Research in Boulder in 1981). They reached more dramatic conclusions, and linked their call for more research with suggestions of strategies for dealing with the problem. But the practical results have been nil - a response that recalls the Sherlockian dog that failed to bark.

Lucid, precise and abundantly informative though these essays are - I noticed only one misprint that might mislead: 200 on p. 107 should be 2,000 - they do not take the process of public education beyond Kellogg and Schware's book. Perhaps that requires a different kind of effort which, though doubtless likely to attract frowns, is in fact no less admirable than the meticulous overview of research issues and conclusions that these authors provide. There may be uncertainties aplenty, but the expectation of a major warming during the twenty-first century now seems to be almost universally shared. In addition to refining the tools by which this process should be measured and assessed, scholars now have the responsibility to specify more urgently the dislocations that are likely to ensue. This book is a foundation for that step: it identifies the topics and findings on which all future work must build. But one has to regret that the learned and superbly qualified authors who produced it have held back from attempting to offer the sharp and unambiguous conclusions that could have served to educate a wider public.

Theodore $K . \quad R a b b$ is a Professor in the Department of History, Princeton University, Princeton, New Jersey 08544, USA. He is coeditor of Climate and History (Princeton University Press, 1981).
Within Saturn's rings - detail of a painting by William K. Hartmann (the original is in colour). The illustration is reproduced from Out of the Cradle: Exploring the Frontiers Beyond Earth, by Hartmann, Ron Miller and Pamela Lee, published by Workman, New York. Price is hbk \$19.95; pbk\$11.95. 